\title{
Nonlinear Vibration Response Analysis and Experimental Verification of Thin-walled Structures to Thermal-acoustic Excitations
}

\author{
SHA Yun-dong, Wang Jian \\ Shenyang Aerospace University \\ Liaoning Province Key Laboratory of Advanced Measurement And Test Technology of Aviation \\ Propulsion Systems \\ Shenyang, China \\ e-mail: j_wang2001@sina.com
}

Keywords: Acoustic loading ways; Vibration response; Thin-walled structures; Coupled FEM/BEM method; Experimental verification

\begin{abstract}
For the nonlinear vibration response problems of aerospace thin-walled structures to thermalacoustic excitation, the theory of structural-acoustic coupling and the coupled FEM/BEM method were used to analyze dynamic response characteristics of super-alloy thin-walled rectangular plates with four edges clamped. Based on different loading ways: diffusion field, progressive wave $0 \% 45^{\circ} / 90^{\circ}$, the theories of buckling and snap-through were employed to study the stress/strain response of structures which were subjected to the different thermal-acoustic loading combinations. The majority of the analyses have dealt with the influence of acoustic loading ways and thermal loadings on structure stress/strain responses, the interaction mechanism of phenomenon of buckling and snap-through on stress/strain responses. Meanwhile, the experimental verifications of nature frequencies and strain have been done, respectively. The analysis results will provide a reference to determine a reasonable fatigue life prediction model.
\end{abstract}

\section{Introduction}

Flight vehicles thin-walled structures bearing thermal-acoustic loadings will yield high frequency vibration stress. Meanwhile, the high acoustic levels can drive the surface panels to occur nonlinear large deflection response. In order to meet the requirements of the structural design of flight vehicles, it is particularly important to carry out the researches for thin-walled strctures.0

Currently, the analysis methods of structural nonlinear response mainly include perturbation method, the FPK equation method, equivalent linearization method (EL), reduced order models (ROM), Galerkin method and Finite element method (FEM). Lee has calculated the stress/strain responses of buckling plates by applying EL method[1-3]. R.Vaicaitis have applied the Galerkin's method to governing partial differential equations (PDE/Galerkin) in conjunction with the Monte Carlo simulation for the prediction of nonlinear response of isotropic and composite panels subjected to acoustic and thermal loads[4,5]. J.Lee has used the PDE/Galerkin method in conjunction with the statistical or equivalent-linearization (EL) technique to study the nonlinear random response of vibrating isotropic plates[6-8]. C. Mei and J.M. Dhainaut have used FEM to calculate the nonlinear random response of panels and shells bearing thermal-acoustic loads[9,10]. Meanwhile, for nonlinear vibration response and fatigue life problems of aerospace thin-walled structures to thermal-acoustic excitation, NASA Lanley research center and Wright-Patterson air force flight dynamics laboratory (AFFDL) of the U.S finished thermal-acoustic test and analyzed the response characteristics of thin-walled panels by using progressive wave tube[11]. J.H. Jacobs has studied the fatigue performances of composite panels subjected to high thermal level excitation by applying random fatigue equipments and progressive wave tube[12]. 
In China, Professor Sha Yun-dong and his coworkers have already done lots of research work about thermal-acoustic response and fatigue life of flight vehicles thin-walled structures, and published numbers of literatures[13-18]. For example, in Ref. 18 Wei jing has calculated dynamic response of titanium alloy plate with four edges simply supported to random excitations and analyzed thermal buckling and nonlinear snap-through responses. As a result, she found that the influence ways of thermal loads and acoustic loads on nonlinear responses existed differences. In this paper, dynamic responses of super-alloy thin-walled rectangular plate with four edges clamped were calculated by using the coupled FEM/BEM method. By combining buckling and snap-through theories, this paper presents the influences of sound pressure level, acoustic loading ways, the incident angle of progressive wave and thermal levels on structural vibration responses.

\section{A Coupled Fem/Bem Theory}

In relevant structural-acoustic coupling, Kirchhoff equation clarified the relationship between the harmonic motion on arbitrary structure surface and the radiation acoustic pressure field around the fluid. It is:

$$
P(\vec{r})=\int_{s}\left\{P\left(\overrightarrow{r_{o}}\right) \frac{\partial G_{\omega}\left(\vec{r}, \omega \mid \vec{r}_{o} w\right)}{\partial \vec{n}}+i \omega \rho_{0} \vec{u}_{n} G_{\omega}\left(\vec{r}, \omega \mid \vec{r}_{o} w\right)\right\} d \vec{S}
$$

Where $\vec{r}$ is the position vector of receptor in sound field; $\vec{r}_{o}$ is the position vector of vibrating structure; $\vec{n}$ is the normal vector; $P\left(\overrightarrow{r_{o}}\right)$ is the surface pressure; $i \omega \rho_{0} \overrightarrow{u_{n}}\left(\overrightarrow{r_{o}}\right)$ is the normal surface acceleration; $G_{\omega}$ is the green function in frequency domain.

Sound field control equation of the BEM is:

$$
[H]\{p\}=\rho_{a} \omega^{2}[G]\left\{u_{a}\right\}
$$

The relationship between sound pressure and modal displacement is:

$$
\begin{gathered}
p(x, y, z, t)=H_{\text {pact }} u_{a}(t) \\
\left\{H_{\text {pact }}\right\}=[H]^{-1}[G][L T]\left\{-\rho_{a} \omega^{2}\right\}
\end{gathered}
$$

Where $H_{\text {pact }}$ is the sound transfer function.

The structural dynamics control equation of coupled BEM/FEM can be written as follows:

$$
[C P L G(\omega)]\{S D(\omega)\}=\left\{S D_{I N}(\omega)\right\}
$$

Where $\{S D(\omega)\}$ is the spectral density function of structural dynamic response; $\left\{S D_{I N}(\omega)\right\}$ is the spectrum density function of external excitation, $[C P L G(\omega)]$ is the overall coupled matrix.

\section{Simulation and Analysis}

Super-alloy with four edges clamped was applied for simulation, and the thickness of plate was 1.5 mm. Table 1 and Table 2 indicate material parameters and thermal-acoustic loads, respectively. Geometry and the extraction positions of strain are shown in figure 1. 
Tab.1 Material parameters of super-alloy in different temperatures

\begin{tabular}{|c|c|c|c|}
\hline Temperature & $\mathbf{2 0}^{\circ} \mathbf{C}$ & $\mathbf{4 5 0}^{\circ} \mathbf{C}$ & $\mathbf{6 0 0}^{\circ} \mathbf{C}$ \\
\hline $\mathbf{E}(\mathbf{G P a})$ & 213 & 170.3 & 155.5 \\
\hline $\boldsymbol{\mu}$ & 0.301 & 0.320 & 0.327 \\
\hline $\boldsymbol{\alpha ( \mathbf { 1 0 } ^ { - 6 } \cdot { } ^ { \circ } \mathbf { C } ^ { - }}$ & 13.4 & 13.7 & 14.4 \\
\hline$\underset{\mathbf{\rho}}{\mathbf{2}}$ & 9.09 & 9.09 & 9.09 \\
\hline $\mathbf{K}\left(\mathbf{W} / \mathbf{C}^{-}\right.$ & 15.4 & 20.1 & 27.1 \\
\hline
\end{tabular}

Tab.2 Thermal-acoustic loading ways

\begin{tabular}{|c|c|c|}
\hline \multicolumn{2}{|c|}{$\begin{array}{c}\text { Types } \\
\text { Loading ways }\end{array}$} & the loads \\
\hline \multicolumn{2}{|c|}{ Thermal load } & $\begin{array}{c}\text { Steady state: } \\
50^{\circ} \mathrm{C} \sim 250^{\circ} \mathrm{C}, \Delta \mathrm{T}=50^{\circ} \mathrm{C}\end{array}$ \\
\hline \multirow{2}{*}{$\begin{array}{c}\text { Acoustic } \\
\text { load }\end{array}$} & $\begin{array}{c}\text { Frequency } \\
\text { range } \\
\text { The overall } \\
\text { SPL }\end{array}$ & $\begin{array}{c}142 \mathrm{~dB} \sim 160 \mathrm{~dB}, \\
50 \mathrm{SPL}=3 \mathrm{~dB}\end{array}$ \\
\cline { 2 - 4 } & $\begin{array}{c}\text { Loading } \\
\text { ways }\end{array}$ & $\begin{array}{c}\text { Diffusion field, } \\
\text { Progressive wave } \\
\left(0^{\circ}, 45^{\circ}, 90^{\circ}\right)\end{array}$ \\
\hline
\end{tabular}

Table 3 shows the first order natural frequency of structure in different temperatures. On the basis of the variation characteristic of the first order natural frequency[18], we can deduce that the critical buckling temperature is around $100^{\circ} \mathrm{C}$. In pre-buckling, the structure is in softening region, stiffness reduces and the first order natural frequency becomes lower with the increasing of temperature; in postbuckling, the structure is in hardening region, stiffness increases and the first order natural frequency becomes higher with the increasing of temperature, as shown in figure 2.

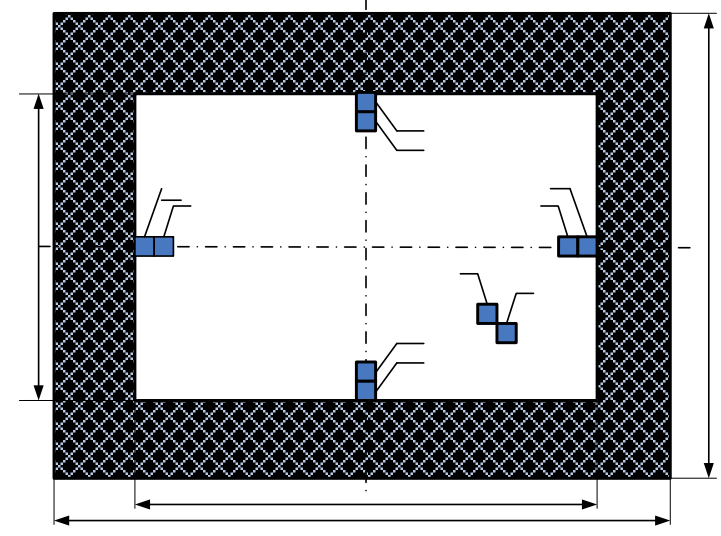

Fig.1 Geometry and the numbers of stress/strain results extraction

Tab.3 The first order natural frequency of four edges clamped plate/Hz

\begin{tabular}{|c|c|c|c|c|c|}
\hline $\begin{array}{c}\text { Temperat } \\
\text { wro }\end{array}$ & $\mathbf{5 0}^{\circ} \mathbf{C}$ & $\mathbf{1 0 0}^{\circ} \mathbf{C}$ & $\mathbf{1 5 0}^{\circ} \mathbf{C}$ & $\mathbf{2 0 0}^{\circ} \mathbf{C}$ & $\mathbf{2 5 0}^{\circ} \mathbf{C}$ \\
\hline $\begin{array}{c}\text { Frequency } \\
/ \mathbf{H z}\end{array}$ & 347 & 257 & 307 & 350 & 481 \\
\hline
\end{tabular}




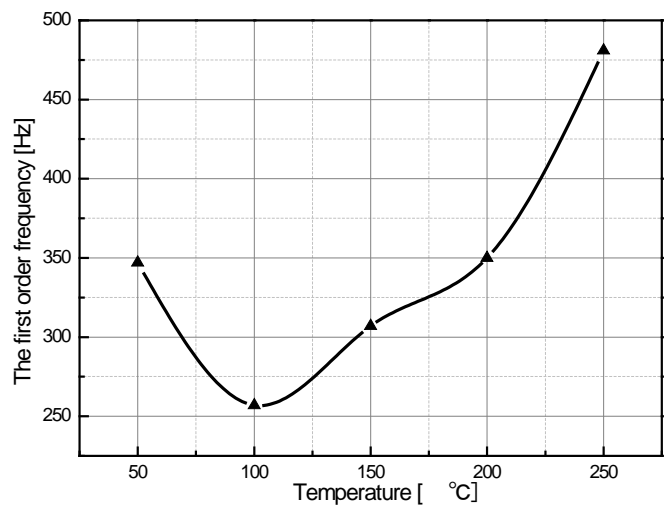

Fig. 2 The first order natural frequency of structure in different temperatures

\section{A. Effects of thermal-acoustic loading ways on responses}

The acoustic loading ways and sound pressure level are determined, and the vibration response of structure mainly distributes in natural frequencies of structure, and there is a significant component in the first order and low order resonance frequencies, presenting the maximum value at the first order frequency, as shown in figure 3.

Figure 3 indicates that in pre-buckling the peak of structure response occurs in high frequency and in post-buckling the peak of structure response occurs in low frequency. In pre-buckling, as thermal stress drives structure to be in softening region, the first order frequency becomes low, but the corresponding peak increases. In post -buckling, snap-through forms are determined by the relative strength of thermal-acoustic loads, 1) once the acoustic load is stronger, structure performances for persistent snap-through, leading structure to be in hardening region and increase the first order frequency, 2) once the thermal load is stronger, structure shows intermittent snap-through, leading structure to be in softening region and reduce the first order frequency.

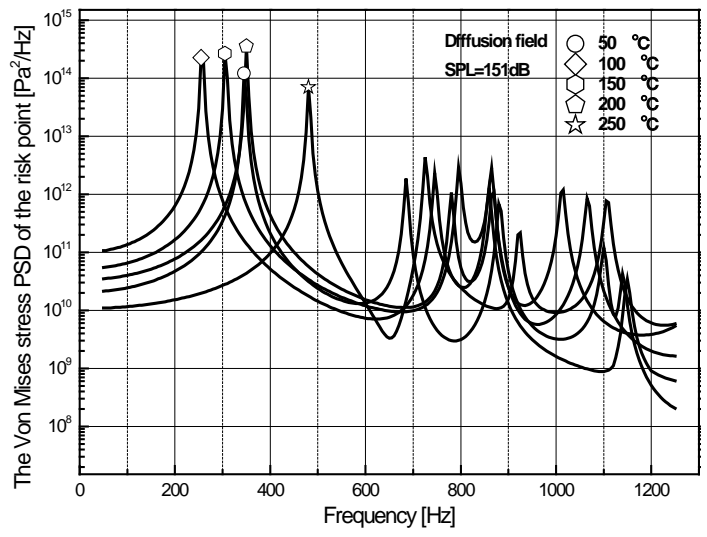

Fig.3 The Von Mises stress PSD of the dangerous position in different temperatures 


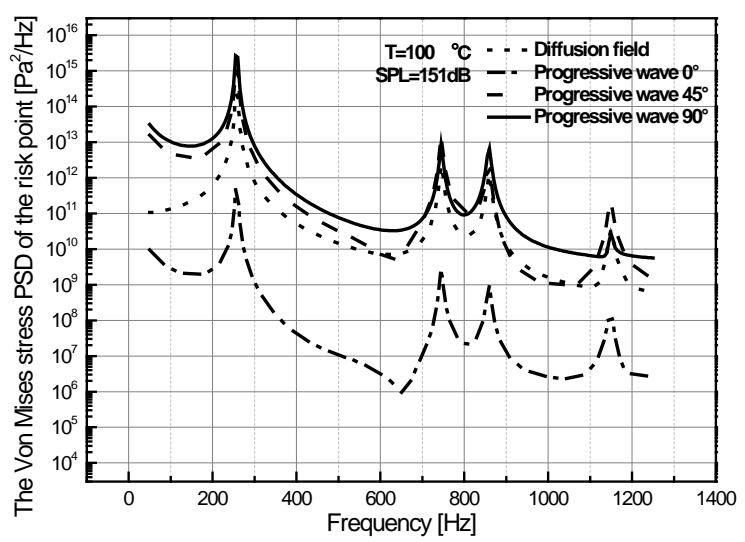

Fig.4 The Von Mises stress PSD of the dangerous position

With the increase of progressive wave incident angle $\left(0^{\circ}-45^{\circ}-90^{\circ}\right)$, the Von Mises stress of structure gradually increases, and the results of progressive wave $0^{\circ}$ and $90^{\circ}$ are respectively corresponding to the minimum value and the maximum value of structure responses, the response results of diffusion are among the progressive wave, as shown in figure 4.

\section{B. Responses in different SPL}

Analysis shows that compared with the first order response, the responses of the second and below could be ignored. In order to simply the analysis process, we can analysis the responses by extracting results in the first order frequency. Figure 5 and figure6 shows that with the increase of SPL until 148dB, the stress/strain responses have an approximately linear increasing trend; after 148dB, structure performs nonlinear large deflection response caused by thermal buckling and acoustic loads, the stress/strain responses show a parabolic increasing trend.

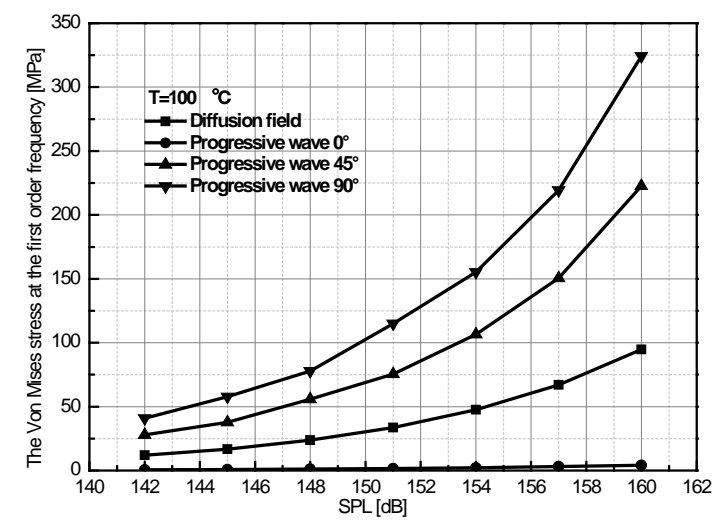

Fig.5 The Von Mises stress of the risk point 


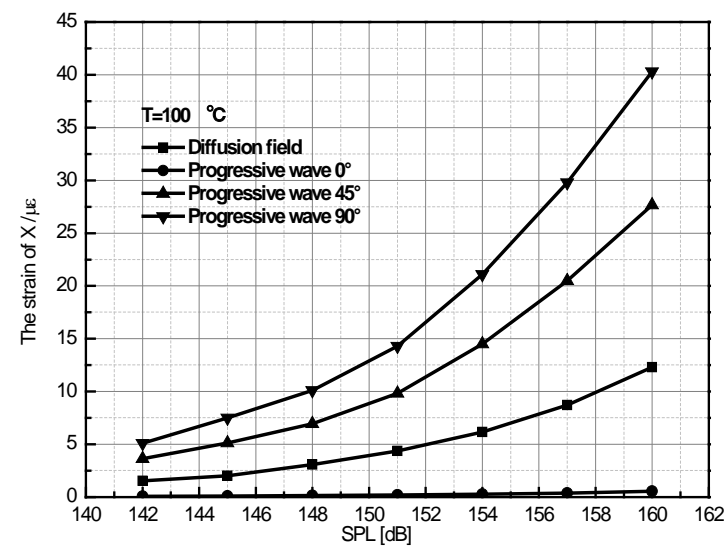

(a) The strain of $X$

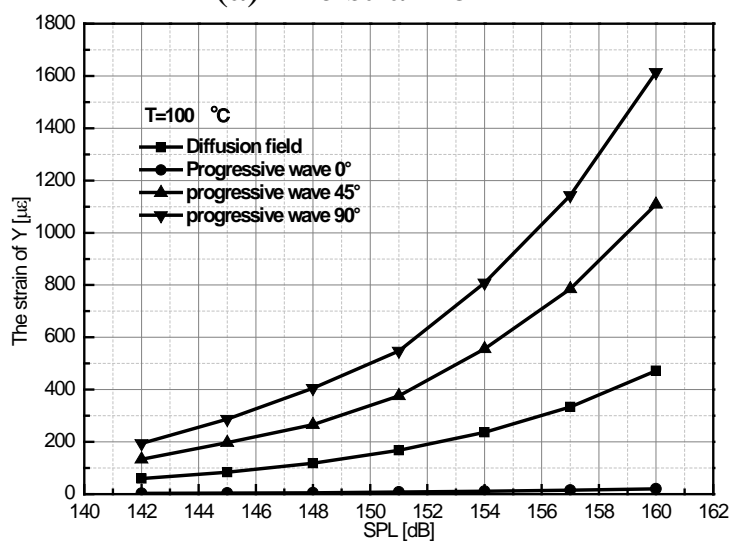

(b) The strain of $\mathrm{Y}$

Fig.6 Unidirectional strain in different acoustic loading ways,

\section{Experimental Verification}

In order to obtain the results of strain and acceleration responses in high thermal-acoustic level, a thermal-acoustic vibration test had been carried out for a super-alloy panel. Figure 7 shows the geometry and the positions which extract the results of strain.

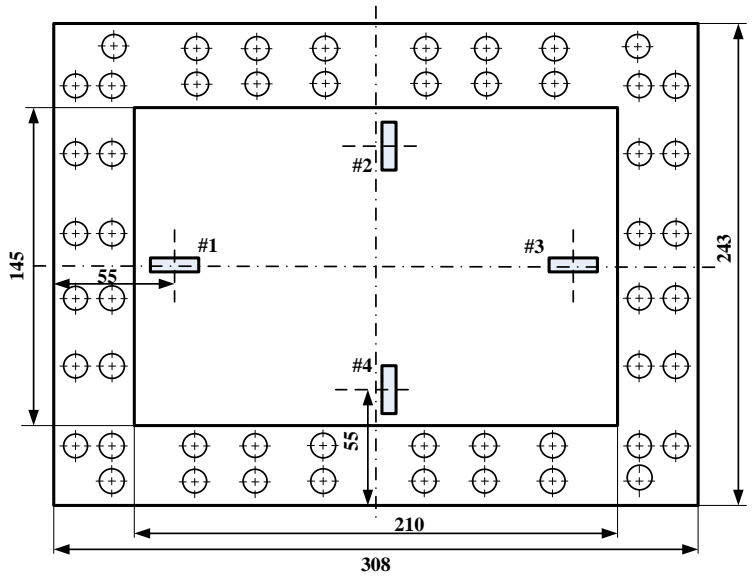

Fig.7 Actual size and exact locations of strain gauges 
Table.4 The thermal-acoustic loading combinations

\begin{tabular}{|c|c|c|}
\hline \multicolumn{2}{|c|}{$\begin{array}{r}\text { Types } \\
\text { Loading ways }\end{array}$} & loads \\
\hline \multicolumn{2}{|c|}{ Thermal load } & $\begin{array}{c}\text { Steady state: } \\
50^{\circ} \mathrm{C} \sim 250^{\circ} \mathrm{C}, \Delta \mathrm{T}=50^{\circ} \mathrm{C}\end{array}$ \\
\hline \multirow{3}{*}{$\begin{array}{l}\text { Acoustic } \\
\text { load }\end{array}$} & $\begin{array}{c}\text { Frequency } \\
\text { range }\end{array}$ & $50 \mathrm{~Hz}-1250 \mathrm{~Hz}, \Delta \mathrm{f}=1 \mathrm{~Hz}$ \\
\hline & $\begin{array}{c}\text { The overall } \\
\text { SPL } \\
\end{array}$ & $\begin{array}{c}142 \mathrm{~dB} \sim 160 \mathrm{~dB} \\
\Delta \mathrm{SPL}=3 \mathrm{~dB}\end{array}$ \\
\hline & $\begin{array}{c}\text { Loading } \\
\text { ways }\end{array}$ & Progressive wave $0^{\circ}$ \\
\hline
\end{tabular}

Through the analysis of test data, the first order frequencies in different temperatures have been obtained. It shows that the simulation values have a pretty fine alignment with the test results, and verifies the modal change rule of structure in pre-buckling and post-buckling. Namely, in pre-buckling, the first order frequency will reduce with the increase of temperature, in post-buckling, the first order frequency will increase with the increase of temperature, as shown in figure 8. In pre-buckling, the representative strain response spectrums of point 1 are shown in figure 9 .

Table.5 The first order natural frequency in different temperatures/Hz

\begin{tabular}{|c|c|c|c|c|c|}
\hline Temperat & $\mathbf{5 0}$ & $\mathbf{1 0 0}$ & $\mathbf{1 5 0}$ & $\mathbf{2 0 0}$ & $\mathbf{2 5 0}$ \\
\hline Test & 347 & 256 & 306 & 350 & 482 \\
\hline Simulatio & 347 & 257 & 307 & 350 & 481 \\
\hline
\end{tabular}

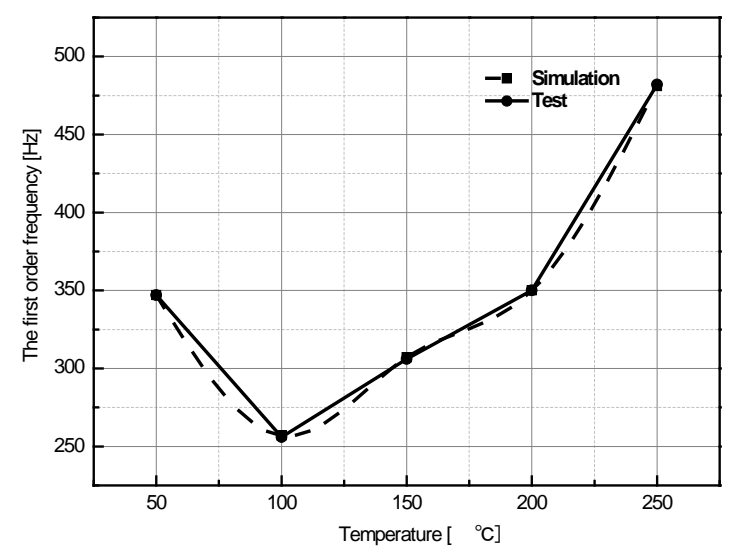

Figure.8 The first order response frequency of structure in different temperatures

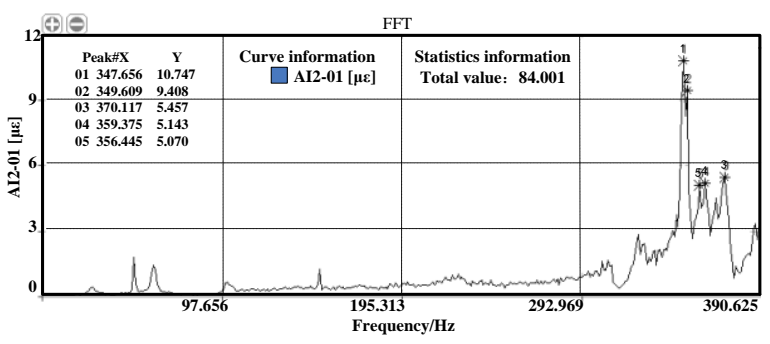

(a) Point $1\left(\mathrm{~T}=50^{\circ} \mathrm{C}, \mathrm{SPL}=151 \mathrm{~dB}\right)$ 


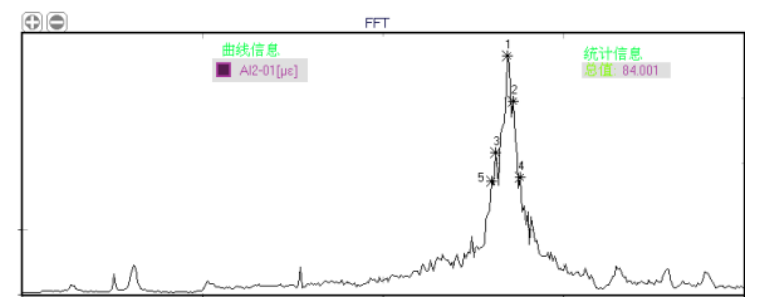

(b) Point $1\left(\mathrm{~T}=100^{\circ} \mathrm{C}, \mathrm{SPL}=151 \mathrm{~dB}\right)$

Figure.9 The strain responses results in frequency domain

Take strain responses results of simulation and the corresponding test results to compare the validation, it indicates that test results have a fine alignment with results of diffusion field, as shown in table 6 . The reason is that the results of responses of progressive wave $0^{\circ}$ will change caused by reflection, refraction and diffraction of sound wave in progressive wave tube

Tab.6 (a) The strains contrast results of short edges midpoints between simulation and experiment / $\mu \varepsilon$

\begin{tabular}{|c|c|c|c|c|c|}
\hline Temperat & $\mathbf{5 0}$ & $\mathbf{1 0 0}$ & $\mathbf{1 5 0}$ & $\mathbf{2 0 0}$ & $\mathbf{2 5 0}$ \\
\hline Test & 10.7 & 15.1 & 16.6 & 12.1 & $\mathbf{1 4}$ \\
\hline Diffusion & 12.6 & 19.9 & 8.9 & 11.6 & 6.5 \\
\hline
\end{tabular}

Tab.6 (b) The strains contrast results of long edges midpoints between simulation and experiment / $\mu \varepsilon$

\begin{tabular}{|c|c|c|c|c|c|}
\hline Temperat & $\mathbf{5 0}$ & $\mathbf{1 0 0}$ & $\mathbf{1 5 0}$ & $\mathbf{2 0 0}$ & $\mathbf{2 5 0}$ \\
\hline Test & 13.9 & 22.5 & 26.0 & 14.4 & 13.1 \\
\hline Diffusion & 4.5 & 8.6 & 15.4 & 25.8 & 14.9 \\
\hline
\end{tabular}

\section{Conclusions}

(1) The thermal-acoustic vibration test verified the change law of the first order frequency. Namely, In pre-buckling, as thermal stress drives structure to be in softening region, the first order frequency becomes low, but the corresponding peak increases. In post -buckling, snap-through forms are determined by the relative strength of thermal-acoustic loads, 1) once acoustic load is stronger, structure performances for persistent snap-through, leading structure to be in hardening region and increase the first order frequency, 2) once thermal load is stronger, structure shows intermittent snap-through, leading structure to be in softening region and reduce the first order frequency. Meanwhile, test strain responses results have a fine alignment with results of diffusion field.

(2) The vibration response of structure mainly distributes in natural frequencies of structure subjected to thermal-acoustic loads, and there is a significant component in the first order and low order resonance frequencies, presenting the maximum value at the first order frequency. With the increase of progressive wave incident angle $\left(0^{\circ}-45^{\circ}-90^{\circ}\right)$, the stress/strain responses of structure gradually increase, and the results of progressive wave $0^{\circ}$ and $90^{\circ}$ are respectively corresponding to the minimum value and the maximum value of structure responses, the response results of diffusion are among the progressive wave.

(3) With the increase of SPL, the stress/strain responses have an approximately linear increasing trend; and then, structure performs nonlinear large deflection response caused by thermal buckling and acoustic loads, the stress/strain responses show a parabolic increasing trend. 


\section{References}

[1] Lee J. Large-Amplitude Plate Vibration in an Elevated Thermal Environment, WL-TR-92-3049[R]. Flight Dynamics Directorate, Wright Laboratory Wright-Patterson AFB, OH, 1992.

[2] Lee J. Displacement and Strain Histograms of Thermally Buckled Composite Plates in Random Vibration: the proceeding of AIAA/ASME/ASCE/AHS/ASC Structures, Structural Dynamics, and Materials Conference and Exhibit, 37th, Salt Lake City, UT, Apr. 15-17, 1996[C]. AIAA, 1996.

[3] Lee J. Displacement and Strain Statistics of Thermally Buckled Plates: the proceeding of AIAA/ASME/ASCE/AHS/ASC Structures, Structural Dynamics, and Materials Conference and Exhibit, 40th, St. Louis, MO, Apr. 12-15, 1999[C]. 1999.

[4] Vaicaitis R. Nonlinear response and sonic fatigue of National Aerospace Space Plane surface panels[J]. Journal of Aircraft, 1994, 31 (1): 10-18.

[5] Vaicaitis R. and Kavallieratos PA. Nonlinear response of composite panels to random excitation[C]. AIAA/ASME/ASCE/AHS/ASC Structures, Structural Dynamics, and Materials Conference, 34th and AIAA/ASME Adaptive Structures Forum 1993, 1:1041-1049.

[6] Lee J. Displacement and strain statistics of thermally buckled plates [C]. AIAA/ASME/ASCE/AHS/ASC Structures, Structural Dynamics, and Materials Conference and Exhibit, 40th 1999, 3:104-110.

[7] Lee J. Displacement and strain histograms of thermally buckled composite plates in random vibration[C]. AIAA/ASME/ASCE/AHS/ASC Structures, Structural Dynamics, and Materials Conference and Exhibit, 37th 1996, 259-266.

[8] Lee Jon. Large-amplitude plate vibration in an elevated thermal environment[R]. 1992.

[9] Mei C, Dhainaut J M, Duan B, Spottswood S M and Wolfe H F. Nonlinear random response of composite panels in an elevated thermal environment[Rt]. 2000

[10] Dhainaut J M, Guo X, Mei C, Spottswood S M and Wolfe H F. Nonlinear random response of panels in an elevated thermal-acoustic environment[J]. Journal of Aircraft, 2003, 40 (4): 683-691

[11] Ng C F, Clevenson S A. High-Intensity Acoustic Tests of a Thermally Stressed Plate[J]. Journal of Aircraft 1991, 28(4): 275-281.

[12] Jacobs J H, Gruensfelder C, Hedgecock C E. Thermal Acoustic Fatigue of Ceramic Matrix Composite Materials: the proceeding of AIAA/ASME/ASCE/AHS/ASC Structures, Structural Dynamics, and Materials Conference, 34th and AIAA/ASME Adaptive Structures Forum[C]. AIAA, 1993.

[13] Y. D. Sha, Z. J. Gao, F. Xue and J. Y. Li. Influence of Thermal Loading on the Dynamic Response of Thin-Walled Structure under Thermo-Acoustic Loading [J]. Applied Mechanics and Materials, 2011,2-3: 876-881.

[14] Y. D. Sha, Z. Zhang, F. T. Zhao and J. Wei. Estimation of Random Sonic Fatigue Life Based on Peak Probability Density of Von Mises Stress[J]. Advanced Materials Research, 2011,199: 913-921. 
[15] Sha Y.D., Li J.Y. and Gao Z.J. Dynamic Response of Pre/Post Buckled Thin-Walled Structure under Thermo-Acoustic Loading[J]. Applied Mechanics and Materials, 2011, 80:536-541.

[16] Sha Y.D., Gao Z.J., Xu F. and Li J.Y. Influence of Thermal Loading on the Dynamic Response of Thin-Walled Structure under Thermo-Acoustic Loading[C]. 2011, 2 876-881.

[17] Sha Y.D., Xu F. and Gao Z.J. Nonlinear Response of Carbon-Carbon Composite Panels Subjected to Thermal-Acoustic Loadings[J]. Applied Mechanics and Materials, 2012, 117:876-881.

[18] Sha Y.D., WeiJ. and Gao Z.J. Nonlinear Characteristics of Thin-walled Structures under Thermoacoustic Loadings[J]. Acta Aeronauticaet Astronautica Sinica, 2013, 34(6) : 1336-1346. 